\title{
Open-source, Custom Interfaces and Devices with Live Coding in Participatory Performance
}

\author{
Camille Baker \\ Digital Media, Engineering and Design \\ Brunel University, Uxbridge \\ United Kingdom \\ camille@swampgirl67.net
}

\begin{abstract}
This paper will discuss the use of open-source, custom interfaces and live coding in artworks and performance practices, using emerging devices that focus on revealing hidden, intimate and sensuous code of the body for manipulation and play. This paper review the new landscape of open-source artworks, with recent examples of such artworks, as well as one by the author, resulting in a new performance aesthetic that uses 'hacked' commercial, mobile and gaming devices for live coding, performance and interactive artworks. It discusses how dancers, live artists, musicians and others are participating in the DIY and 'Maker' movement, to create exciting wearable electronics and mobile applications for performance enhancement. The author will consider the possibilities of playful, expressive, gestural, and live coding, as well as using the DIY Maker ethos in multi-sensory participatory performances with new devices. The author's own artistic research has involved re-combinatory practices and hybridisations of participatory performance, mobile media, wearable biofeedback sensors and live database interaction in a recent performance project MINDtouch. Her new collaborative work Hacking the Body, is about making participatory performances and interactive dance pieces that expose 'code' of the inner body.
\end{abstract}

Open-source DIY. Custom interfaces and devices. Live coding. Participatory performance. Wearable electronics.

\section{INTRODUCTION}

Art has always responded to the social currents of the time and milieu it is situated within, and even with so many still working in traditional forms of art and performance practices, such as painting, sculpture, mixed media, drawing, music, opera or ballet, most artists today cannot ignore the impact of technological and communication media on modern living, and in turn on their artistic practice.

Whether it is the increasing mobility and globalisation, or environmental issues and the search for sustainable practices, or the influence of the smartphones, tablet computing and handheld devices, or techniques such as laser cutting and 3D printing - emerging technologies have had great influence on current art and performance practices. The use of digital technology, electronic devices and digital networking in artistic practice, as well as access to the abundance of online knowledge, reveals enormous opportunities for the creation of new forms of art and for the innovation. It also enables new forms of interaction with audiences and the public, which has increasingly the blurred boundaries between creators and audiences, giving rise to the significant potential for learning and engagement between them.

The artistic landscape has been rapidly shifting around us recently; as tablet painters, sketchers and smartphone photographers appear everywhere. The evolution of internet and communications technology has formed, informed and reformed art practice by infusing it with fresh and innovative approaches, tools, interaction, and imagination - as can be seen at the annual SIGGRAPH Conference and Expo, or the roving International Symposium of Electronic Art (ISEA) and the many other technology-based art conferences and festivals around the world each year. 


\section{THE EVOLUTION OF TECHNOLOGICAL ART}

Interactions between technology-based art and can be traced to the 1950's when such works as the 'Oscillon 40' made by Ben Laposky, who according to the Victoria and Albert Museum website "...used an oscilloscope to manipulate electronic waves that appeared on the small fluorescent screen... displaying the wave shape of an electric signal... constantly moving and undulating on the display..." (Accessed April 2013). As early as the 1960s, electronic instruments began to be used to create music (for example as described in "White Heat Cold Logic: British Computer Art 1960-1980" (Brown et al.: 2009).

Artists have been often included in big corporate R\&D departments from as early as the 60's, to help foster more aesthetic or cutting edge approaches to technological development, such as the artist in residencies in places like IBM with William Latham as their artist in residence, 1990 (Brown, 1996) and Sony Computer Science Laboratory with Atau Tanaka as one of their artists in residence (20012007).

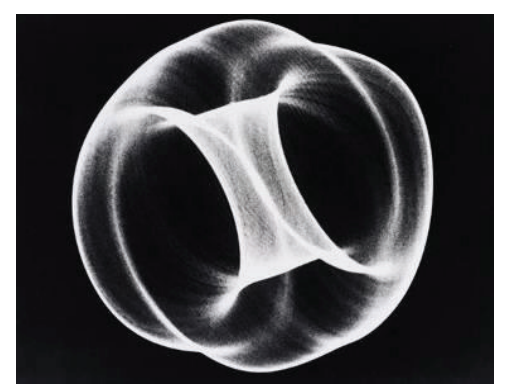

Figure 1: Ben Laposky, 'Oscillon 40', 1952

Today the interface between technology and art is exponentially increasing in size and scope, attracting artists from all varieties of art making and backgrounds.

\section{THE RISE OF OPEN-SOURCE TECHNOLOGIES IN SOCIETY}

The growth of the Open Data movement, along with initiatives such as Smart Cities, Open Data Cities, Climate Code and mySociety, has brought open-source initiatives into the public eye, and fuelled a growth in the DIY and maker movement.

'Hacking' as a practice and ethos is being reclaimed, from the negative connotations of stealing information, music and films online and through peer-to-peer networks, to its original definition of taking apart and repurposing commercial technologies, now mixed with opensource technologies, for new innovations and artworks. Hacking is back to being "a material practice that produces differences in computer, network and communications technologies" (Jordan, 2008:12), displaying a degree of technically specific excellence. It is again seen as way of thinking of new permutations of more established techniques to "...open up a vital window into possibilities, sensibilities and ethics of twentyfirst century cultures and societies" (Jordan, 2008:15). Specifically, the traditional hacker ethics, primarily focused on sharing, openness, collaboration, and engaging in the hands-on imperative, is taking over how technology is used and art is made today.

These developments are no longer underground and subversive now that many mobile phones have Android, an open-source operating system, which enables exponential growth in mobile software development around the world. This development and the accessibility of the tools enables more people to engage in and learn programming and electronics, to get involved in technology progress, making their own software applications and electronic devices. In recent years, Nokia had two waves of open calls were made for projects and artists in 2009 for "free" R\&D to use in their opensource mobile platforms such as MeeGo, Nokia N900 had Maemo 5 (Linus based system) and the open-source version of Symbian. CERN and The Centre for Computational Neuroscience and Robotics have had artists in residence on on-going basis now. With Google's Android OS (and Apple's more limited developer program), mobile opensource application development has exploded, with huge opportunities for creativity and digital artwork.

The open-source electronic, digital and Internet revolution opened up a new landscape of opportunities and creative applications for art driven by the ever-emerging variety of devices, systems and interfaces with entirely new capabilities. There are now a plethora of different tools and technologies either in use, or in experimental stages a large number are using open-source technologies. These tools enhance and facilitate creative processes for artists, whether they are working alone or in collaboration with other artists or technologists. Projects such as nuigroup (nuigroup.com) and OpenNI (openni.org) provide access to cutting-edge $\mathrm{HCl}$ techniques, while Arduino and Processing allow easy creation of software and hardware, targeted towards both creative practice and education. These tools require other open platforms, technologies and networks in order to work, without encountering economic and security barriers.

Open-source programming environments for creativity have exploded in popularity among DIY makers and crafters in recent years, as well as with 
techno-savvy artists, such as: Processing, Arduino, Pure Data, Apple's Quartz Composer, openFrameworks, VVVV and many others, as well as the more traditional programming languages of $\mathrm{C}++$ and Java. "Maker" communities have emerged around the world where engineers, programmers and artists or crafters get together, pool their resources and support each other to make new unusual projects - outside of traditional corporate and academic research environments (such as the London HackSpace, or the worldwide Dorkbot or Maker Faire communities).

These communities produce and develop software tools and hardware, which have spread exponentially since Linux first became available, especially with the Creative Commons copyright (Copyleft) and other such licensing methods taking more prominence (i.e. FLOSS etc.). Projects like Living Labs (http://www.openlivinglabs.eu/) create real-life test and experimentation environments, using innovation dynamics from prototyping processes and co-creation, where users and producers co-create innovations. Living Labs have been characterised by the European Commission as Public-Private-People Partnerships (PPPP) for user-driven open innovation. Many digital art and technology festivals are sponsoring 'hack' Meetups and events where artists and technologists meet for the first time, bringing sometimes only their ideas, skills and perhaps their laptops or DIY electronics kits, to build something together by the end of the day. This flurry of 'maker' 'crafting' or commoner art/ICT collaborations is increasing innovation and enhancing creativity, is sure to have a huge influence on future art/technology collaboration and innovation.

\section{OPEN-SOURCE TECHNOLOGICAL ART TODAY}

Artists are always adapting to and developing new technologies while finding new ways to create compelling visual and sensual works. This increase of such powerful technologies have given birth to new forms of socially connected, interactive and collaborative creation, new ways of experiencing art (e.g. 3D projections of artworks, virtual tours of artists' works, cultural context webs), as well as to the abundance of totally new forms of cultural and educational media content, including e-books, iPads, e-paintings, digital 3-D/ interactive/ immersive videos.

Many musicians, artists, software developers and technologists have been increasingly making their own open-source tools and applications for their projects and performances, as well as making them available for others to use and reuse. Currently, there is a proliferation of tools for musicians incorporating tablet computers into their composition and performances as instruments and controllers.

Conceptual aspects of the 'database', with visual methods for tagging and categorising media in the network create ambient narrative constructions and performance interactions. Generative elements are incorporated through the custom iPhone and iPad tools, as well as inexpensive electronics kits with easy to learn open-source programming environments and other technologies. The possibilities for 'hacking' (the non-criminal variety) and live coding for more expressive, live and performative artworks have given artists with the flexibility to learn or teach themselves programming a huge advantage and 'canvas' for art-making in the digital and electronic domain.

Many artists are now finding new ways to create their work using open-source tools to make custom software and apps for performative, generative or database projects that take advantage of mobile media, or wearable and gaming devices, as well as video, sensors, musical instruments, network and tracking or mapping devices (i.e. RFID GPS), using shared forums and tutorials such as www.creativeapplications.org - the field is rapidly expanding exponentially. Recently, these works include working with custom software and mobile 'apps' which take advantage of mobile media tools (GPS, Accelerometers, QR readers, AR apps etc.) and gestural gaming interfaces (Wii, Kinect, OmniTouch), generative coding and other exciting tools they have made using open-source programming techniques and resources; the field is rapidly expanding exponentially.

An example of an artist using primarily open-source tools for her digital 'paintings' and interactive visual artworks, is the London-based artist, Kasia Molga, trained as a painter and animator, who now uses interactive live data feeds and SMS to create digital paintings and other generative and interactive digital works. BBC Screens commissions large interactive screens projects, and they commissioned one of Molga's works for Glastonbury 2010, (go to www.kasiamolga.net or see her these works shown in the Vague Terrain issue 22 on Mobile Performance 2012).

There are many other examples of electronic, digital and network technologies as an integral part of a dance, theatre or musical performance or exhibition, exploring possibilities of the tools and finding innovative ways to engage audiences. The Victoria and Albert Museum had a weekend of open source creativity as part of their digital art exhibition Decode in 2010/2011 in London and one of the showcases was artists who made innovative 
performative or interactive projects with Nokia's open source platform the N900.

\section{MINDTOUCH \& HACKING THE BODY}

The mobile media performance project, MINDtouch: Ephemeral Transference, a PhD art research work was completed in 2010 and published in 2011. It explored notions of ephemeral transference, distance collaboration and participant as performer to study 'presence' and 'liveness' emerging from the use of wireless mobile technologies within real-time, mobile performance contexts, using mobile phones and physiological wearable devices. The intent was to create a paradox in the notions of liveness and presence, or the feeling of 'being there'.

MINDtouch explored embodied, non-verbal interaction using wearable biosensing devices and mobile phones as the 'interfaces' to connect bodies, in a weave of layered media during social events. It sought to uncover how bodily sensations, perceptions, and interactions could be meaningfully utilised and expressed visually. It proposed that the mobile videophone become a new way to communicate non-verbally, in real time, across different physical and technological environments and locations. The goal was to expand and explore more meaningful exchanges between remote groups of people.

MINDtouch was created as a participatory media artwork that was designed for "Social Mobile VJing" using for media phones. Participatory, mobile media social events enabled telematic presence and liveness, aided by the embodied physiological sensors, to intensify the interaction and engagement. Presence of participants was transformed into a digital video collage, allowing them to 'touch' and 'play' with others, remotely, through the network. To practically investigate these concepts, a mobile media performance series was created. Ways to simulate, emulate or even facilitate connections and the sensing of "feltness", presence and/or liveness, co-presence and collaboration were explored with participants within mobile performance events.

The project tried to exemplify liveness and presence within the context of a series of live, 'staged', iterative, 'scratch' mobile media social events. These 'scratch' or performance experiments involved improvisation and experimentation through generative, participatory, collaboratively mixed mobile video visualisations, triggered by biosensor data from participants' bodies. The live events involved participants engaging in improvisation and experimentation with the mobile video activities.
Users 'VJ-ed' or mixed video from a database live, and using their body data with wireless sensors they had abstract visual conversations with other mobile users, creating a collaborative, telematic collage of externalised body sensations. MINDtouch participatory events involved creating a mobile, networked performance that utilised a database of archived of streamed and/or archived video clips created by video enabled mobile phones, to be retrieved, streamed and remixed during a live visuals performance(s). The live event performative, collaborative, non-linear narrative montage or "remix" is then streamed back out to anyone's phone and the Internet, using real-time video mixing and streaming, and accessing a remote server and mobile network. It was about the transmitting the sense of liveness and presence, through visual manifestations of embodied experiences through the mobile network.

Custom software was created, using some opensource tools such as Quartz Composer, to take the body data from the sensors to mix and stream the video from the database of clips, added visual effects, then streamed the mixed video back out through the server, ideally in real time. The resulting video collage became a collaborative, narrative and global mobile-cast, converging distinct technologies and practices, bringing all the remote audience members to share and interact with the generative visual collage of other people's video. The body data that controlled the video effects and mixing was displayed or projected for the live participants and streamed for remote participants.

Programming for this project was done using a mix of proprietary and open-source technologies (Nokia's open-source version Symbian, Apple's Quartz Composer and other tools), by artist/technologists Michael Markert, Evan Raskob and Manjit Bedi and Huw Williams in collaboration with me. We began to work with off-the-shelf sensors and electronics, which Michael Market, assembled and programmed.

We used free, open-source coding options because the project budget did not allow for purchase of commercial products. This meant sacrificing some quality and fidelity in the sensor data (less critical for the project than for medical applications), and we had to 'daisy-chain' the technologies and find workaround options in order to try to stay true to the project goals, but this approach lent us more freedom. Thus, we used the alternative approach to using expensive medical commercial products, by buying and wiring up cheaper DIY sensors and connecting them to a customised Arduino microcontroller connected to Bluetooth became a much cheaper solution, with full flexibility to design a simple and reasonable communications protocol. 
Instead of having to deal with such an intense system made by commercial companies, the advantages of using open-source and DIY electronics included the ability to use other existing open source solutions (modules, both in terms of software and hardware) and a wider appeal to other makers and artists and a sharing of our tools.

The current collaborative work in development Hacking the Body with dance artist/choreographer Kate Sicchio - discussed in another paper for EVA, is about making participatory performances and interactive dance pieces that expose 'code' of the inner body through three 'Hacks'. This three-part performance exploration, uses biofeedback sensor, mobile phones, the Kinect, Processing, Layar and other mobile apps for body data, gestural, video sensing and generative mobile video performance installations and participatory interaction. The project is focussed on using the hacker ethos and methodology to create performance works, as well as a creating a new methodology for working with the body in performance and performance creation through a hacking lens.

See my portfolio online at: www.swampgirl67.net

\section{REFERENCES}

Aicardi, C. (2011) "Nexus of Art and Science: The Centre for Computational Neuroscience and Robotics at University of Sussex," ed. Lanfranco Aceti, Leonardo Electronic Almanac (Mish Mash) 17, no. 1, pp. 56-81. Available online at: http://www.leoalmanac.org/nexus-of-art-andscience-lea-magazine-article/ (Accessed April 3, 2013).

Ahmed, S.U., Camerano, C., Fortuna, L., Frasca, M., Jaccheri, L. (2009) Information technology and Art: Concepts and State of Practice, Handbook of Digital Media in Entertainment and Arts, Borko, F. (Ed.), New York, NY: Springer US. Available online http://prosjekt.idi.ntnu.no/sart/publications/BChapte r2 IT\&Art.pdf (Accessed January 10, 2013).

Alleyne, B. (2011) "We are all hackers now": critical sociological reflections on the hacking phenomenon', Under Review, pp. 1-32, Goldsmiths Research Online, [Online] Available at http://eprints.gold.ac.uk/6305 (Accessed August 21, 2012).

Baker, C.C. (curator) (2012) "Mobile Performance", Vague Terrain, Issue 22. Available online http://www.vagueterrain.net/journal22 (Accessed April 3, 2013).

Baker, C.C. (2010) "MINDtouch - Ephemeral Transference: Liveness' in Networked Performance with Mobile Devices", PhD Thesis, published in University of East London Library in print with DVD support materials and the British Library in digital form, December 2010.

Bourriaud, N. $(1998,2002)$ Relational Aesthetics, Dijon, France: Les Presses du Réel, pp. 84-102.

Brown, P. et al. (2009) White Heat Cold Logic: British Computer Art 1960-1980, Leonardo Book Series, Cambridge, MA: The MIT Press.

Brown, P. (1996) "Emergent Behaviours: Towards computational aesthetics', Artlink: Art in the Electronic Landscape, Vol 16, no 2\&3. Available online at

https://www.artlink.com.au/articles/457/emergentbehaviours-towards-computational-aesthet/ (Accessed April 3, 2013).

Chatzichristodoulou, M., Jeffries, J. and Zerihan, R. (2009) Interfaces of Performance, Farnham, UK: Ashgate Publishing.

Cogan, R. (1991) "Varèse: An Oppositional Sonic Poetics," Sonus, Vol. XI, no. 2, p. 26-35. Available online at

https://ccrma.stanford.edu/CCRMA/Courses/154/va rese.html (Accessed April 4, 2013).

Dwyer, T. (1971) Composing with Tape Recorders: Musique Concrète for Beginners. London and New York: Oxford University Press.

Galloway, A., Brucker-Cohen, J., Gaye, L., Goodman, E., and Hill, D. (2004) 'Design for hackability'. In Proceedings of the 5th conference on Designing interactive systems: processes, practices, methods, and techniques (DIS '04). New York, NY: ACM, 363-366.

Grant, C (2010) "David Hockney's instant iPad art", BBC News: Technology. Available online at http://www.bbc.co.uk/news/technology-11666162 (Accessed April 5, 2012).

Hockney, D, (2012) iPad Drawings at the Royal Academy in London. Available online at http://www.hockneypictures.com/iphone pages/iph one etcetera-01.php (Accessed April 3, 2013).

Hyde, J. (2012) "Me and My Shadow", Body $>$ Data>Space project, performed at The National Theatre in London. Available online at http://www.bodydataspace. net/projects/meandmys hadow/ (Accessed April 3, 2013).

Jordan, T., Hacking: Digital Media and Technological Determinism, Digital Media and Society, Polity, Cambridge, UK, 2008.

Kozel, S. (2007) Closer: Performance, Technologies, Phenomenology, Cambridge, MA: The MIT Press.

Kresin, F., Reitenbach, M., Rennen, E., van Dijk, D., Sabine Wildevuur (eds.) (2011) Users as Designers: A hands-on approach to Creative 
Research, Waag Society. Available online at http://Waag.org/sites/Waag/files/public/Publicaties/ Users as Designers.pdf (Accessed January 10, 2013)

Lynch, D. (2010) Handset Review Nokia N900, technology blog. Available online at http://danlynch.org/blog/2010/01/n900-review/ (Accessed April 5, 2013)

Miller, A.I. (2000) Insights of a Genius. Imagery and Creativity in Science and Art, London: The MIT Press.

Shanken, E.A. (2002) Art in the Information Age: Technology and Conceptual Art LEONARDO, Vol. 35, No. 4, Cambridge, MA: The MIT Press. pp. 433-438. Available online at

http://artexetra.files.wordpress.com/2009/02/shank enartinfoage.pdf (Accessed April 3, 2013)

Shaughnessy, H. (2013) "Apple's Rise and Nokia's Fall Highlight Platform Strategy Essentials", Forbes Magazine online March 8, 2013 issue. Available online at http://www.forbes.com/sites/haydnshaughnessy/20 13/03/08/apples-rise-and-nokias-fall-highlightplatform-strategy-essentials/2/ (Accessed April 4, 2013).

Shapiro, P., ed. (2000) Modulations: a History of Electronic Music: Throbbing Words on Sound, New York: Caipirinha Productions.

Wilson, S. (2010) Art + Science Now: How scientific research and technological innovation are becoming key to 21st-century aesthetics, London: Thames \& Hudson.

Research department, Victoria \& Albert museum (date unknown), A History Of Computer Art. Available online at http://www.vam.ac.uk/content/articles/a/computerart-history/ (Accessed April 3, 2013).

Soderberg, J. (2008) Hacking Capitalism. The Free and Open Source Software Movement. New York: Routledge. 